\title{
Moment based Object Classification from Shapes
}

\author{
G. Karuna \\ Research Scholar, JNTUH, \\ Hyderabad
}

\author{
P. Chandrasekhar Reddy, \\ Ph.D. \\ Professor, JNTUCEH, \\ Hyderabad
}

\author{
M. Srinivasa Rao, Ph.D. \\ Professor, SIT, JNTUH, \\ Hyderabad
}

\begin{abstract}
A flexible object recognition system is considered which can compute the good features for high classification of objects. To characterize an output class or object usage of appropriate features is vital for all classification problems. Moment invariant functions are very useful for object classification, regardless of its orientation, size and position. The main features leading us to our objective are representations of objects using 2D images. The proposed paper focus on, the classification performance of classifiers with moment-based feature sets is introduced after only efficient feature extraction. The experimental results shows that the proposed feature descriptor performs well with existing texture descriptors in terms of classification accuracy.
\end{abstract}

\section{Keywords}

Moment invariants, feature extraction, shape, object recognition/classification.

\section{INTRODUCTION}

One of the basic and most fundamental problems being addressed in computer vision is the problem of object recognition and detection. It is the question of what objects or object types we see in an image and how to determine their precise location and segmentation. Answering this question with high accuracy will have an enormous impact and diverse consequences in the field of machine perception and beyond. It is a fundamental step towards image and video understanding.

Object recognition is defined as the process of extracting information such as name, size, shape, position, pose, and functions related to the object. In this paper, we restrict the definition to extracting object's identification and shape information only. Representing shape is a challenging task. In fact, unlike local characteristics like color, which can be uniquely determined by a small set of parameters or texture, which has been successfully captured by using statistical descriptors, the visual information conveyed by a shape of more global nature and easily perceived by humans, is hard to represent in an appropriate way. This paper deals with two dimensional (2D) shape representations for object recognition When the 2D shapes describe simply connected regions, researchers have used contour-based descriptions, e.g., [1, 2, 3].

The use of appropriate features to characterize an output class or object is critical for all classification problems. Moment invariants are important shape descriptors in computer vision. There are two types of shape descriptors: contour-based shape descriptors and region-based shape descriptors [5]. Regular moment invariants are one of the most popular and widely used contour-based shape descriptors is a set of derived by $\mathrm{Hu}$ [6]. These geometrical moment invariants have been then extended to larger sets by Wong \& Siu [7] and the other forms Liao \& Pawlak [8]. Zernike velocity moments were developed by Shutler \& Nixon [4], Mohamed Rizon etal [9], to describe an object using not only its shape, but also its motion throughout an image. But these approaches have shown some limited success to some problems such as illumination change, target object is obscured due to the presence of the other object which can interfere with recognition process such as the fronds.

Feature extraction and object recognition are large research areas in the field of image processing and computer vision. Recognition is largely based on the matching of descriptions of shapes. Numerous shape description techniques have been developed, such as analysis of scalar features (dimensions, area, number of corners etc.), Fourier descriptors, moment invariants and boundary chain coding. These techniques are well understood when applied to images and have been developed to describe shapes irrespective of position, orientation and scale. They can be easily applied to vector graphical shapes. This paper describes experiments, which apply circle moment invariants to the problem.

Experiments carried out to circle moment invariants as features of object recognition, which produce an optimal result for the problem of shape description.

This paper is organized as follows: Proposed system, feature vector representation and classification algorithm are discussed in Section 2. The experimental results and analysis are drawn in Section 3. Finally the conclusions are given in Section 4 .

\section{PROPOSED ALGORITHM}

An essential issue in the field of pattern analysis is the recognition of objects regardless of their position, size and orientation. We will now give a brief introduction of the system we are proposing in this paper. The process starts with the decomposition of objects into entities that will then serve as the basis for our recognition system. Broadly speaking our system can be divided in three steps: preprocessing, feature extraction, recognition. In the preprocessing stage, extract the shape of the image. After having extracted the shapes, feature descriptors are created. These descriptors are made specifically to be invariant representations entailing as much important information of the shape as possible. They are created in such a way that they can be fed into a KNN classifier and allow for recognition.

The object classification algorithm containing six steps as given below:

1. Convert the given color image into grey scale image.

2. Convert the grey scale image into binary image by using threshold.

3. Apply the proposed shape representation scheme using circular shifting method [10] to obtain boundary of the binary image, that represents the shape of the object in an efficient way.

4. Evaluate CMIs on the obtained boundary image.

5. Calculate the average of CMIs for each group of objects and place them in feature database.

6. Plot the classification graph for all CMIs and determine 
the classification rate.

\subsection{Circle Moment Invariants (CMI)}

Similarity of the images can be measured in terms of their features. It is of great importance to define pattern features for characterizing the leaf images. For this purpose, circle moment invariants (CMI) are applied on the extracted shape boundary image and are proven to be invariant under object translation (change of position), scale (change of size) and rotation (change of orientation) [11]. Shape boundary of the binary images proposed by Karuna etal [10].

Circle moment invariants (CMIs) are constant for circle-based geometrical distributed images. The 2D circle moment of order $(p+q)$ of a digital image $f(x, y)$ is defined in Equation (1) and translation invariance is defined in Equation (2)

$$
\begin{gathered}
\mathrm{m}_{\mathrm{pq}}=\sum_{\mathrm{x}} \sum_{\mathrm{y}} \mathrm{x}^{\mathrm{p}} \mathrm{y}^{\mathrm{p}} \mathrm{f}(\mathrm{x}, \mathrm{y}) \\
\mu_{\mathrm{pq}}=\sum_{\mathrm{x}=0}^{\mathrm{M}-1} \sum_{\mathrm{y}=0}^{\mathrm{N}-1}\left|\left(\mathrm{x}-\mathrm{x}_{0}\right)^{\mathrm{p}} \|\left(\mathrm{y}-\mathrm{y}_{0}\right)^{\mathrm{q}}\right| \mathrm{f}(\mathrm{x}, \mathrm{y})
\end{gathered}
$$

where $\mathrm{p}=0,1,2, \ldots$ and $\mathrm{q}=0,1,2, \ldots, \mathrm{x} 0$ and $\mathrm{y} 0$ represent the centre of the circle of the image. Based on the circle moments $\mu \mathrm{pq}$, the following eight CMI's for describing the features of the boundary images, which are defined as follows:

$$
\begin{aligned}
& \mu_{00}=\sum_{x=0}^{M-1} \sum_{y=0}^{N-1} f(x, y) \\
& \mu_{11}=\sum_{x=0}^{M-1} \sum_{y=0}^{N-1}\left|\left(x-x_{0}\right)\right|\left|\left(y-y_{0}\right)\right| f(x, y) \\
& \mu_{20}=\sum_{x=0}^{M-1} \sum_{y=0}^{N-1} \mid\left(x-x_{0}\right)^{2} f(x, y) \\
& \mu_{02}=\sum_{x=0}^{M-1} \sum_{y=0}^{N-1} \mid\left(y-y_{0}\right)^{2} f(x, y) \\
& \mu_{21}=\sum_{x=0}^{M-1} \sum_{y=0}^{N-1}\left|\left(x-x_{0}\right)^{2}\right|\left(y-y_{0}\right) \mid f(x, y) \\
& \mu_{12}=\sum_{x=0}^{M-1} \sum_{y=0}^{N-1}\left|\left(x-x_{0}\right)\right|\left(y-y_{0}\right)^{2} f(x, y) \\
& \mu_{03}=\sum_{x=0}^{M-1} \quad \sum_{y=0}^{N-1}\left|\left(y-y_{0}\right)\right|^{3} f(x, y) \\
& \mu_{30}=\left.\sum_{x=0}^{M-1} \sum_{x=0}^{M-1}\left(x-x_{0}\right)\right|^{3}
\end{aligned}
$$

To verify the CMIs, an experiment is conducted with extracted boundary images [10].

\subsection{Classification Algorithm}

The next step, after the feature vectors establishment classification of objects to the appropriate classes are performed, which is performed by specific modules called 'classifiers' and their performance is highly depended on their structure and the discrimination power of the features being used. For the sake of experiments, four types of K-NN classifiers are used. Four well-known distances from the literature are Euclidean [12], Logarithmic [12], Correlation Coefficient [12] and Hausdorff [13] are selected and presented in the following,

Euclidean distance $\left.-d_{I}(P, S)=\sqrt{\sum_{i=1}^{n}\left(p_{i}\right.}-s_{i}\right)^{2}$

Logarithmic Magnitude distance $-d_{2}(P, S)=\sqrt{\sum_{i=1}^{n}\left(\log ||_{i} \mid\right.}-$ $\left.\log \left|s_{i}\right|\right)^{2}$

Correlation coefficient method $-d_{3}(P, S)=$

$\frac{\sum_{i=1}^{n} p_{i} s_{i}}{\left.\left.\mid \sum_{i=1}^{n} \log \left(p_{i}\right)^{2}\right)\left.\right|^{1 / 2} \mid \sum_{i=1}^{n} \log \left(s_{i}\right)^{2}\right)\left.\right|^{1 / 2}}$

HAusdorff distance $-d_{4}(P, S)=\max (h(P, S), h(S, P))$, where $h(P, S)=$ $\max _{\mathrm{pEP}} \min _{\mathrm{seS}}\|\mathrm{p}-\mathrm{s}\|$

The above formulas measure the distance between two vectors $\mathrm{P}=[\mathrm{p} 1, \mathrm{p} 2, \mathrm{p} 3, \ldots, \mathrm{pn}], \mathrm{S}=[\mathrm{s} 1, \mathrm{~s} 2, \mathrm{~s} 3, \ldots, \mathrm{sn}]$, which are defined in the $\mathrm{n}$ space. It has to be noted that the above measures tend to 0 for the case of two equal vectors, except $\mathrm{d} 3$ which gives 1 , since it counts the similarity of the two vectors. Finally, these measures are treated as objective functions aimed to be minimized (d1, d2, d4) or maximized (d3).

\section{EXPERIMENTAL RESULTS}

The Leaf images are taken from Flavia dataset [14] contains 1907 images of 32 kinds of leaves with green color (50 to 77 images for each species). Figure 1 shows Flavia dataset of 32 leaves with original names which are used for classification purpose.

To evaluate a good classification and recognition of objects circle moment invariants are applied on the boundary images. These features give considerable information about the global properties of a shape (boundary) image. The moment invariants (CMIs) are stored in the feature database which is used to train, validate and test the feature database. Finally, a LOOM (leaveone-out-method) is used to guarantee strict separation of test and training set with the maximization of number of training images. Then four types of K-NN distance classifiers are used as feature selection mechanism for classification of objects. According to a parameter $\mathrm{k}$, the $\mathrm{k}$ nearest vectors are kept to find the most representative class; i.e., the most represented class within the $\mathrm{k}$ neighbours. The success of object classification is measured using Equation (15)

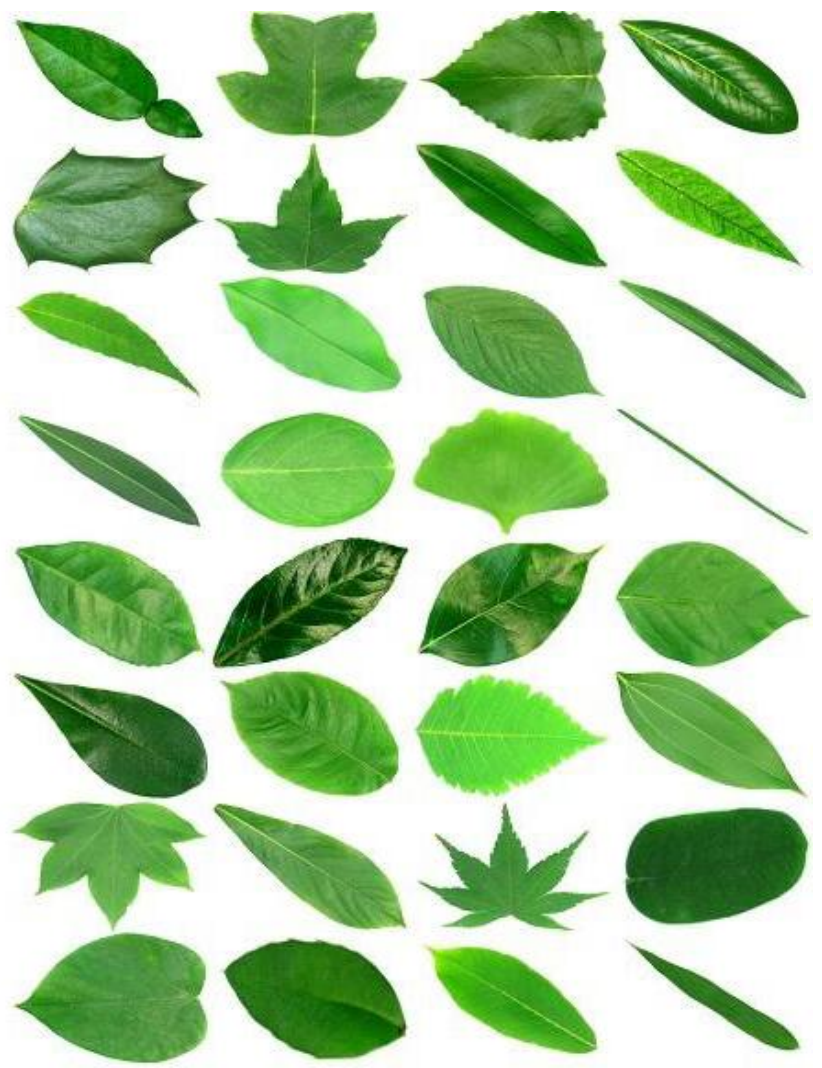

Fig.1: Flavia Dataset: Pubescent bamboo, Chinese horse chestnut, Anhui Barberry, Chinese redbud, True indigo, Japanese maple, Nanmu, Castor aralia, Chinese cinnamon, Deodar, Ginkgo, Crape myrtle, Oleander, Yew plum pine, Japanese Flowering Cherry, Glossy Privet, Chinese Toon, Peach, Goldenrain tree, Big-fruited Holly, Japanese cheesewood, Wintersweet, Camphor tree, Japan Arrowwood, Sweet osmanthus, Ford Woodlotus, Trident maple, Beale's 
barberry, Southern magnolia, Canadian poplar, Chinese tulip tree, Tangerine.

$$
\mathrm{CCR}(\%)=\frac{\text { total number of corrency classified objects }}{\text { total number of classifiedobjects }} \mathrm{X} 100
$$

By observing the results of 1 able 1 , clearly evident that one of the distance classifier correlation coefficient method (d3) from the proposed shape representation scheme classifies the given Flavia database. Euclidean distance classifier (d1) and Hausdorff distance (d4) classifiers shows more or less same value. Logarthemic Magnitude distance classifier failed in classification.

\section{CONCLUSION}

In general there is no best feature for image classification because each classification technique has its own strengths and weaknesses and is suitable for particular kind of problems. The selection of an appropriate feature descriptor must reflect a specific object classification / recognition task in hand and usually need to be obtained through experimental evaluation. In order to find the appropriate feature descriptor circle moment invariants are evaluated for classification of objects based on shape. Then K-NN classifiers are applied, only correlation coefficient revealed as the benchmark classifier. The experimental results exhibit that the proposed feature descriptor shows more accurately than classic shape feature descriptors.

\section{REFERENCES}

[1] T. Crimmins, "A complete set of Fourier descriptors for two-dimensional shapes," IEEE T-SMC, vol. 12, 1982.

[2] G. Chauang and C. Kuo, "Wavelet Descriptor of Planar Curves: Theory and Applications," IEEE T-IP, vol. 5, 1996

[3] Bartolini, P. Ciaccia, and M. Patella, "Warp: Accurate Retrieval of Shapes using Phase of Fourier Descriptors and Time Warping Distance," IEEE T-PAMI, vol. 27, no. $1,2005$.

[4] Shutler J D, Nixon M S "Zernike velocity moments for description and recognition of moving shapes," Proc. BMVC, pp: 705-714, 2001.

[5] Kim W-K, Sung Y, "A region-based shape descriptor using Zernike moments," Signal Process. Image Commun., Vol.16, pp:95-102, 2000.

[6] Hu M "Visual pattern recognition by moment invariants," IRE Trans. Inf. Theor. IT-8, pp:179-187, 1962.

[7] Wong W H, Siu W C "Improved digital filter structure for fast moment computation," IEE Proc. Vision, Image Signal Process., Vol.46, pp: 73-79, 1999.

[8] Liao S X, Pawlak M "On the accuracy of Zernike moments for image analysis," IEEE Trans. Pattern Anal. Mach. Intell., Vol.20, pp: 1358-1364, 1998.

[9] Mohamed Rizon, Haniza Yazid, “Object Detection using
Geometric Invariant Moment," American Journal of Applied Sciences, Vol.2, Issue:6, pp:1876-1878, 2006.

[10] G.Karuna, B.Sujatha, "An Efficient Representation of Shape for Object Recognition and Classification using Circular Shift Method," Int. Journal of Scientific \& Engineering Research, Volume 4, Issue 12, pp: 703-707, December-2013, ISSN 2229-5518.

[11] Chaur-Chin Chien, "Improved Moment Invariants for Shape Discrimination," Pattern Recognition, Vol. 26, No. 5, pp. 683-686, 1993.

[12] R. Mukundan, K.R. Ramakrishnan, Moment Functions in Image analysis, World Scientific Publisher, Singapore, 1998.

[13] D.P. Huttenlocher, G.A. Klanderman, W.J. Rucklidge, "Comparing images using the Hausdorff distance," IEEE Transactions on Pattern Analysis and Machine Intelligence, Vol.15, No.9, pp:850-863, 1993.

[14] Wu G.S., Bao F.S., Xu E.Y., Wang Y.X., Yi-Fan Chang Y.F., Xiang Q.L.,"A Leaf Recognition Algorithm for Plant classification Using Probabilistic Neural Network," IEEE International Symposium on Signal Processing and Information Technology, 2007.

\section{AUTHOUR'S PROFILE}

G. Karuna is currently working as an Assistant Professor in Computer Science and Engineering Department, Gokaraju Rangaraju Institute of Engineering and Technology, Hyderabad, A.P., India. She is working towards her Ph.D. at Jawaharlal Nehru Technological University, Hyderabad, A.P., India. She received her M.Tech. in Computer Science and Engineering from Jawaharlal Nehru Technological University, Hyderabad, India in 2010. She did her M.C.A from IGNOU, India in 2004. She has eight years experience of teaching undergraduate students and post graduate students. She has published 5 research papers in National and International journals. Her research interests are in the areas of Image Processing, Image Watermarking, and Cryptography and Network Security.

P. Chandrasekhar Reddy, working as Professor in coordination, Department of ECE, JNTUH, Hyderabad. He received his $\mathrm{Ph} . \mathrm{D}$ in the area of Computer Networks in Computer Science \& Engineering from JNTU, Hyderabad. He has published 25 National and International Journals. His areas of interests are, Computer Networks, Image Processing and Network Security.

M. Srinivasa Rao, working as Professor in the Department of CSE, SIT, JNTUH, Hyderabad. He received his Ph.D in Computer Science \& Engineering from JNTUH, Hyderabad. He has more than 26 years of experience in teaching, Software development and guided 200 post-graduate thesis. He has published 25 National and International Journals. His areas of interest are Web Technologies, Artificial Neural Networks, Software Testing Tools and IT Workshop. 
Table 1: Average classification rate of Flavia database images of proposed CMI's with four different classifiers

\begin{tabular}{|c|c|c|c|c|c|c|c|c|c|}
\hline \multirow[b]{2}{*}{$\begin{array}{l}\text { Object } \\
\text { Image }\end{array}$} & \multicolumn{4}{|c|}{$\%$ of correct classification rate } & \multirow[b]{2}{*}{$\begin{array}{l}\text { Object } \\
\text { Image }\end{array}$} & \multicolumn{4}{|c|}{$\%$ of correct classification rate } \\
\hline & $\begin{array}{l}\text { Euclidean } \\
\text { distance } \\
\left(d_{1}\right)\end{array}$ & $\begin{array}{l}\text { Logarithmic } \\
\text { Magnitude } \\
\text { distance }\left(\mathrm{d}_{2}\right)\end{array}$ & $\begin{array}{c}\text { Correlation } \\
\text { coefficient } \\
\text { method } \\
\left(\mathrm{d}_{3}\right)\end{array}$ & $\begin{array}{l}\text { Hausdorff } \\
\text { distance } \\
\left(\mathrm{d}_{4}\right)\end{array}$ & & $\begin{array}{l}\text { Euclidean } \\
\text { distance } \\
\left(\mathrm{d}_{1}\right)\end{array}$ & $\begin{array}{l}\text { Logarithmic } \\
\text { Magnitude } \\
\text { distance }\left(\mathrm{d}_{2}\right)\end{array}$ & $\begin{array}{l}\text { Correlation } \\
\text { coefficient } \\
\text { method } \\
\left(\mathrm{d}_{3}\right)\end{array}$ & $\begin{array}{l}\text { Hausdorff } \\
\text { distance } \\
\left(\mathrm{d}_{4}\right)\end{array}$ \\
\hline $\begin{array}{l}\text { Pubescent } \\
\text { bamboo }\end{array}$ & 95.8 & 95.7 & 96.7 & 96.9 & $\begin{array}{l}\text { Chineese } \\
\text { Toon }\end{array}$ & 98.75 & 90.8 & 97.5 & 96.7 \\
\hline $\begin{array}{l}\text { Chinese } \\
\text { horse } \\
\text { chestnut }\end{array}$ & 95 & 95.5 & 95.7 & 95.8 & Peach & 97.5 & 91.5 & 97.5 & 97.5 \\
\hline $\begin{array}{l}\text { Anhui } \\
\text { Barberry }\end{array}$ & 98.75 & 94.5 & 98.8 & 98 & $\begin{array}{l}\text { Goldenrain } \\
\text { tree }\end{array}$ & 97 & 87.5 & 98.7 & 92.6 \\
\hline $\begin{array}{l}\text { Chinese } \\
\text { redbud }\end{array}$ & 98 & 98.5 & 98.7 & 95.8 & $\begin{array}{l}\text { Big-fruited } \\
\text { holly }\end{array}$ & 97.75 & 91.7 & 95.75 & 96.25 \\
\hline True indigo & 96 & 91.1 & 97.5 & 96.5 & $\begin{array}{c}\text { Japaneese } \\
\text { cheesewood }\end{array}$ & 94.5 & 95.8 & 95.7 & 96.8 \\
\hline \multirow{2}{*}{$\begin{array}{l}\text { Japanese } \\
\text { maple }\end{array}$} & \multirow{2}{*}{95.5} & \multirow{2}{*}{91.7} & \multirow{2}{*}{96.7} & \multirow{2}{*}{95.8} & Winter sweet & 96 & 92.5 & 96.5 & 90.4 \\
\hline & & & & & Camphor tree & 95.25 & 81.5 & 95.5 & 95.4 \\
\hline Nanmu & 96 & 93 & 96.8 & 94.75 & \multirow{2}{*}{$\begin{array}{c}\text { Japan Arrow } \\
\text { wood }\end{array}$} & \multirow[b]{2}{*}{98.5} & \multirow[b]{2}{*}{91.1} & \multirow[b]{2}{*}{98.4} & \\
\hline $\begin{array}{l}\text { Castor } \\
\text { aralia }\end{array}$ & 96.25 & 89 & 97.5 & 97 & & & & & 97.6 \\
\hline $\begin{array}{l}\text { Chinese } \\
\text { cinnamon }\end{array}$ & 98 & 93.3 & 98.7 & 97.4 & $\begin{array}{c}\text { Sweet } \\
\text { osmanthus }\end{array}$ & 96.25 & 91.8 & 96.7 & 93.8 \\
\hline Deodar & 99 & 79.2 & 99.7 & 97.7 & $\begin{array}{c}\text { Ford } \\
\text { Woodlotus }\end{array}$ & 97.5 & 95.5 & 99.5 & 94.56 \\
\hline Ginkgo & 95.5 & 83.3 & 96.7 & 91.2 & Trident & 95.25 & 89.6 & 95.5 & \\
\hline \multirow{2}{*}{$\begin{array}{l}\text { Crape } \\
\text { myrtle }\end{array}$} & \multirow{2}{*}{96} & \multirow{2}{*}{94.7} & \multirow{2}{*}{93.7} & \multirow[t]{2}{*}{95.8} & & & & & 90.1 \\
\hline & & & & & Beale's & 95.75 & 95.75 & 98 & 96 \\
\hline Oleander & 98.2 & 95.8 & 98.3 & 97.5 & & & & & \\
\hline $\begin{array}{c}\text { Yew plum } \\
\text { pine }\end{array}$ & 95.5 & 87.5 & 95.7 & 94.2 & $\begin{array}{l}\text { Southern } \\
\text { magnolia }\end{array}$ & 98.25 & 97 & 98.25 & 97.5 \\
\hline $\begin{array}{l}\text { Japanese } \\
\text { flowering }\end{array}$ & 96 & 90.8 & 96 & & $\begin{array}{c}\text { Canadian } \\
\text { poplar }\end{array}$ & 95.5 & 93 & 96 & 95.5 \\
\hline cherry & & & & 94.2 & $\begin{array}{l}\text { Chinese } \\
\text { Tulip tree }\end{array}$ & 97 & 91 & 97.5 & 96 \\
\hline $\begin{array}{l}\text { Glossy } \\
\text { privet }\end{array}$ & 95 & 91.7 & 95.7 & 94.7 & Tangerine & 98.5 & 93.5 & 99 & 98 \\
\hline
\end{tabular}

